\title{
Nutrition and food security policy in the Islamic Republic of Iran: situation analysis and roadmap towards 2021
}

Behzad Damari ${ }^{1}$, Zahra Abdollahi ${ }^{2}$, Majid Hajifaraji ${ }^{3}$ and Arezoo Rezazadeh ${ }^{4}$

${ }^{1}$ National Institute of Health Researches, Tehran University of Medical Science and Health Services, Tehran, Islamic Republic of Iran. ${ }^{2}$ Office of Community Nutrition, Deputy of Health, Iran Ministry of Health Treatment and Medical Education, Tehran, Islamic Republic of Iran. ${ }^{3}$ Department of Nutrition \& Food Policy Making Research, National Nutrition \& Food Technology Research Institute, Faculty of Nutrition \& Food Technology, Shahid Beheshti University of Medical Sciences, Tehran, Islamic Republic of Iran. ${ }^{4}$ Department of Community Nutrition, National Nutrition and Food Technology Research Institute, Faculty of Nutrition Sciences and Food Technology, Shahid Behehshti University of Medical Sciences, Tehran, Islamic Republic of Iran (Correspondence to: A. Rezazadeh: arezoo.rezazadeh@gmail.com)

\begin{abstract}
Background: All government policies and programmes for food and nutrition security should include providing healthy food, as well as providing economic and social availability for all people.

Aim: This study aimed to analyse the current situation of Iranian food and nutrition security and establish a road map towards 2021.
\end{abstract}

Methods: The applied methods were situation analysis and a mixed qualitative-quantitative method. The conceptual method used for developing this national document encompassed three areas: sustainable food supply, food safety and nutrition.

Results: The outcomes of the Iranian food and nutrition security system in the past three decades include development of management infrastructure and improvement in food and nutrition security status. However, analysis of current programmes showed that there were some overlapping, intertwining and parallel works in the responsibilities of related organizations in the field of supervision of food safety (from production to supply). The national document produced as the outcome of this paper was communicated by the Iranian Ministry of Health in 2012 and has been running for 2 years. Selected ministries are responsible for implementation of 20 national programmes by the end of the 5th Economic, Social and Cultural Development Programme (2016-2011). The consensus of stakeholders by the end of the 6th Development Programme (2021) is to put all of the provinces in a safe or very safe situation in terms of food and nutrition security.

Conclusion: The most important challenge in establishing national documents is to make them operational. This aim was achieved by an intersectoral nutrition and food security working group, which produced a general memorandum of understanding with the main organizations, the media, universities and private sector.

Keywords: Policy, food and nutrition security, situation analysis, roadmap, Iran

Citation: Damari B; Abdollahi Z; Hajifaraji M; Rezazadeh A. Nutrition and food security policy in the Islamic Republic of Iran: situational analysis and roadmap towards 2021. East Mediterr Health J. 2018;24(2):177-188. https://doi.org/10.26719/2018.24.2.177.

Received: 07/10/15; accepted: 05/03/17

Copyright (C) World Health Organization (WHO) 2018. Some rights reserved. This work is available under the CC BY-NC-SA 3.0 IGO license (https:// creativecommons.org/licenses/by-nc-sa/3.o/igo).

\section{Introduction}

Food security and nutrition security are two different and complementary terms that are considered to be health-related social factors (1). According to the Food and Agriculture Organization (FAO) of the United Nations, "food security is the physical, social and economic access of all people, at all times, to sufficient, safe and nutritious food, for a healthy and active life" (2). Nutrition security is a more comprehensive concept, defined as "physical, social and economic access of all people, at all times (3), to adequate, safe and nutritious food, with effective cellular intake, for a healthy, active and happy life" $(4,5)$. In 2015, the World Health Organization (WHO) focused on food safety under the slogan "From farm to plate, make food safe", to highlight the importance of this issue, especially in view of the global nature of food supply, and to emphasize the important role of governments, manufacturers, retailers and the public in ensuring food safety (3).

The WHO report of 2010 on nutritional policies in the Islamic Republic of Iran shows that this country, like $25 \%$ of others, does not yet have any significant policy or programme for solving nutritional problems such as nutritional imbalances, under- and overnutrition, obesity and chronic diseases, and micronutrient deficiencies among children and adolescents. In the WHO Eastern Mediterranean Region, most member states have policies for controlling overnutrition and inadequate care of women's nutritional deficiencies. Policies and programmes for confronting the nutritional problems of crises have not been considered adequately. The WHO report indicates that most of the tools for implementing the policies focus on informative approaches like guidelines, labelling, and promoting healthy eating in the media. In most countries of the Region. There are 
coordination mechanisms in the Ministry of Health and there are partial collaborations between the Departments of Education, Agriculture, Food and Social Welfare on this matter. In a few East Asian countries coordination mechanisms for nutrition and food security programmes are under the supervision of the prime minister or president. Their power, however, is usually limited to allocation of responsibilities, and rarely generalizes to budget allocation (6).

Rapid urbanization, changes in lifestyle and nutritional transition are rapidly taking place in many countries in the Region (3) such as the Islamic Republic of Iran (7). In recent decades, Iranian dietary patterns have been changing from healthy traditional diets to western diets (high consumption of red and processed meats, refined grains and fried foods) and unhealthy dietary habits concurrent with reduced physical activity (8-10).

Food insecurity is one of the main concerns of the5th National Development Programme of the Islamic Republic of Iran (2011-2016). This economic, social and cultural programme comprises a variety of challenges in stewardship, financing, resources generation and service provision functions of the existing health system (11). A meta-analysis on Iranian experiential/perception-based studies showed an increase in the prevalence of mild (from $8.8 \%$ to $9.3 \%$ ) and moderate (from $5.4 \%$ to $5.6 \%$ ) food insecurity and almost no change in severe food insecurity (from 3.8\% and 3.7\%) between 1994 and 2004. Prevalence of food insecurity (moderate to severe) based on household income/expenditure surveys was 10\% (12).

The Iranian High Council of Health and Nutrition Security was established in 2004. Several programmes $(8-20)$ have been implemented in the past few years in this field at the Ministry of Health and even some intersectorial documents have been compiled. However, weak operationalization of the recommended strategies, lack of an organized response system of monitoring and evaluation, weakness of intersectorial coordination, and deficiency of peripheral capacities (in provinces and townships) have inhibited the programmes.

The present study aimed to describe the process of developing a national action plan for improving food and nutrition security, through reviewing and analysing the documents and programmes based on the ideas of intersectorial experts, so that: (1) a common language and commitment (inter/intrasectorial) could be established for the goals and strategies of improving food and nutrition security by the stakeholders; (2) an appropriate basis could be formed for operationalizing the rules and regulations, and institutionalizing the previous programmes; and (3) increased advocacy efforts could be made for the resources and obligations of improving food and nutrition security, including the working structure at township, province and headquarter levels.

\section{Methods}

To develop, approve and establish a national document for food and nutrition security, a situation analysis was carried out through a mixed qualitative-quantitative research method, whereby the dominant component was qualitative. The qualitative method was implemented as a content analysis method and the quantitative method as a nested method within a qualitative section by descriptive analysis of secondary data, aiming at analysing indicators of food and nutrition security. This document contained 3 main parts: recognition, orientation and establishment systems. The steps of compiling, approving and primary establishment of the document for food and nutrition security are presented in Table 1. Explanation and analysis of the current situation and determination of the orientation (including landscape, strategic objectives and interventions) were conducted in the 3 areas of sustainable food supply, food safety and nutrition. The situational analysis lasted 9 months and the next steps were as follows.

\section{Step 1: Data collection}

The following methods were used for data collection.

1. Revision of all the published secondary data on food and nutrition security and upstream documents for describing the current situation and its trends during the past decade. The secondary data included annual reports of the Department of Nutrition , Ministry of Health; reports of monitoring and evaluation of the national nutrition programmes; governmental and ministerial rules and regulations on food and nutrition security; documents about previous strategic plans and current programmes; and reports of research and collected national consensus. Access to the documents and evaluation reports of other organizations was conducted through the Parliamentary Research Centre and they were reviewed and reported by collaboration with the Deputy Director of the Centre.

2. According to this review, the indicators of food and nutrition security at different levels, including effects, outcomes, outputs, processes and inputs have been extracted and summarized in the food and nutrition security profile.

3. Revision and analysis of the documents for the current programmes of the organizations. All of the pilot or implemented programmes and documents of the Iranian Ministry of Health on food and nutrition security were collected, studied and analysed through interview with the Director-General and officers of the Department of Nutrition. Those documents included annual reports of the Department of $\mathrm{Nu}$ trition, reports of monitoring and evaluation of the nutritional programmes, the Ministry of Health rules and regulations on food and nutrition security, documents of the previous strategic plans and the current programmes, and reports of research and national consensus data.

4. Revision of international documents: reports of WHO, World Bank, food and nutrition security programmes in Europe and Africa, and international food organizations were studied and summarized to 


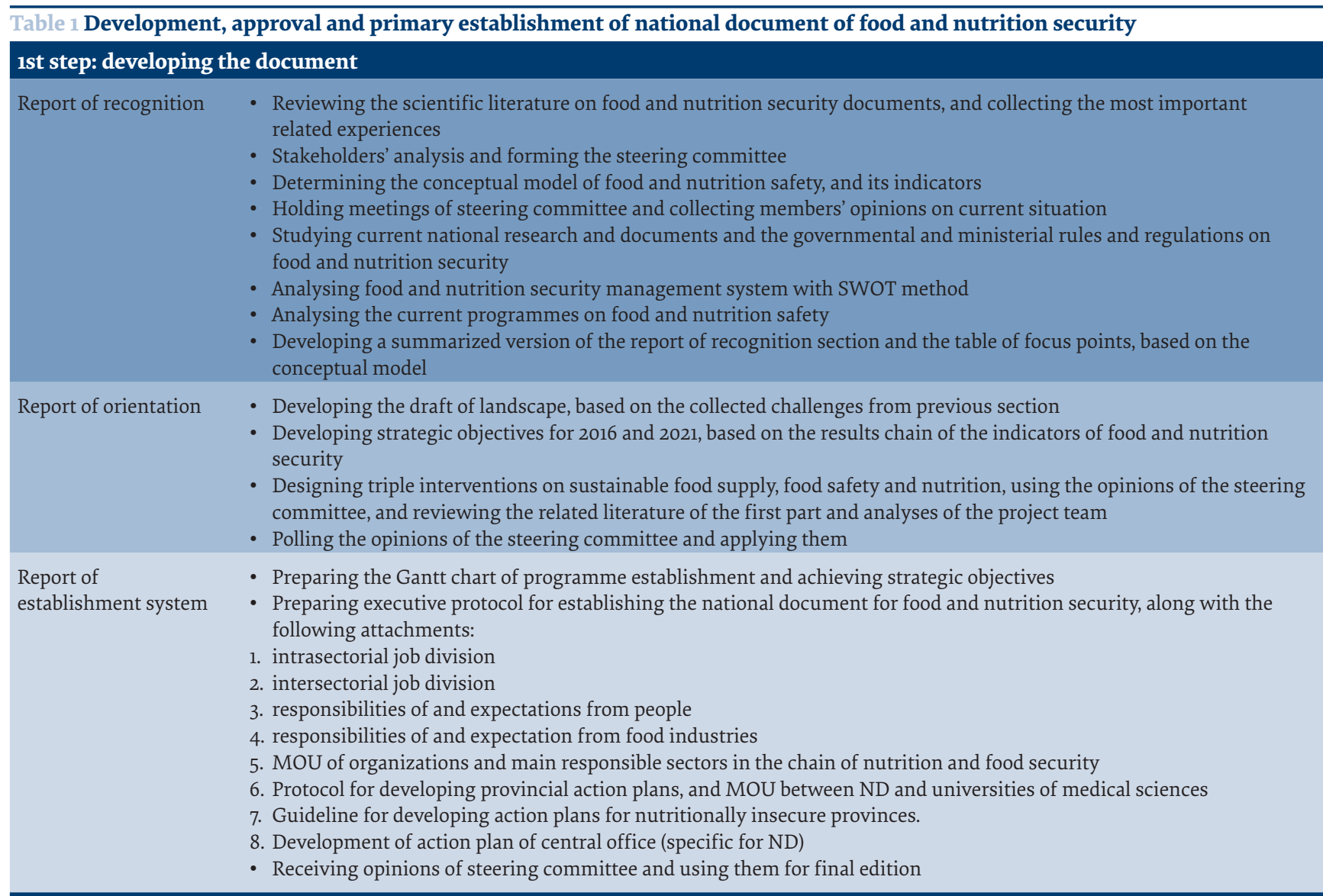

2nd step: advocacy for approving the document

1. Analysis of stakeholders for determining the key persons for decision making

2. Holding a meeting with Deputy for Public Health Affairs, in order to justify and advocate the food and nutrition document

3. Notifying the protocol for developing the action plan, and drafting the document by the Deputy for Public Health Affairs

4. Holding a meeting with previous and current Ministers of Health, and obtaining their support for placing the document on the agenda of the High Council of Health and Nutrition Security, and notifying the document by the High Council of Health and Nutrition Security to all ministers and provincial governor-generals.

5. Intrasectorial notification of the document to the Deputies of MOHME and chancellors of the universities of medical sciences

6. Intersectorial notification of the document to the Minister of Agriculture, Minister of Industry, Mining and Commerce, Minister of Cooperation, Labour and Social Welfare, and Directors of National Standard Organization, High Council of Provinces, National Broadcasting Organization, and Chambers of Commerce, and suggesting a seminar for introducing the national document on food and nutrition security

7. Negotiating with members of Parliamentary Health Commission and convincing them for legislating on food and nutrition security

\section{3rd step: laying ground for primary establishment}

1. Informing experts at MOHME about the national document and the methods for its establishment

2. Holding advocacy meeting with the stakeholders of the 7 provinces with food and nutrition insecurity, presenting methods for remedying the situation, and providing related guidelines

3. Developing the headquarters' action plan for 2013, with the help of ND experts

4. Notifying 49 MOUs with 49 universities of medical sciences in 31 provinces, for starting Implementation of the food and nutrition document in 2013

5. Determining members of the expert working group on food and nutrition security (under the High Council of Health and Nutrition Security) and delivering their statements to another organization

6. Informing the community through mass media about developing, approving and establishing the document

MoHME = Ministry of Health and Medical Education; $\mathrm{MoU}$ = memorandum of understanding; ND = Nutrition Department; $S W O T=$ strengths, weaknesses, opportunities and threats.

be used as guidelines for developing the conceptual model and list of indicators, and analysing the situation and new strategies and approaches in designing the interventions and establishing the programme.

\section{Step 2: Stakeholder analysis and designing the conceptual framework}

Stakeholders' analysis was conducted using an interestinfuence/power matrix (13) and technical steering committee in public, private and nongovernmental sectors. The steering committee being composed of the representatives of intersectorial organizations, was formed by selection of the Deputy for Public Health Affairs in the Iranian Ministry of Health. The committee was responsible for criticizing and approving 3 main parts of the document.

To conduct interviews, an intentional sampling method was used and members of the steering 
committee were selected as interviewees. All people were familiarized with the items of the interview in a justification meeting. All interviews were conducted by a social medicine specialist. Overall, 10 members of the steering committee were structure-interviewed and the interviews were classified into 3 main questions: (1) how is the food and nutrition security status in the Islamic Republic of Iran? (2) Which factors influence it? (3) What solutions are recommended to improve the current situation?

The questionnaires were sent to the interviewees by email and consequently a face-to-face interview was arranged. The average duration of each interview was about 30 minutes. All interviews were recorded with the permission of the interviewees and transcribed by a single interviewer.

In addition, according to the data obtained from the previous methods, the management system for food and nutrition security in both internal and external environments was analysed in terms of the following components. The internal environment consisted of the following 3 components: (1) food and nutrition security stewardship, including implementation of the national food and nutrition security programme, intrasectorial coordination, advocacy, supervision, related regulations, inter-sectorial coordination and public participation; (2) resources, including provision of financial resources, human resources, and food and nutrition security related information; and (3) services of health improvement, prevention, treatment and rehabilitation.

The external environment was analysed in 2 parts of near and far environments. In the near environment, conditions of participation and attitude of the stakeholders, and in the far environment, economic, social, political, technological, international and environmental factors were analysed and finally, a draft was prepared.

After analysis of food and nutrition security management status and applying the results of the reviewed references, a draft document was prepared in 3 areas of (1) current situation (indicators of food and nutrition security; trends, strengths and weaknesses of the management system of food and nutrition security; and analysis of current programmes); (2) the effective factors in the current situation of food and nutrition security; and (3) interventions in 3 levels of sustainable food supply, food safety and nutrition (Table 2 ).

\section{Step 3: Focus group discussion, integration and establishment of the national food and nutrition security policy}

The national food and nutrition security policy document was studied and criticized in 3 workshops. In each workshop, members of the steering committee were divided into 3 groups and recorded the information that was collected with the help of facilitators familiar with the matter and focus group discussion. After each workshop, the document was amended based on the recommendations of the participants. Members of the steering committee were a set of managers (food and nutrition related managers from ministries and organizations other than the Ministry of Health); representatives of the private sector; representative of urban or rural councils; and experts including faculty members and/or directors of scientific associations. For selecting the stakeholders, the 2 criteria of legal responsibility and efficiency in improving food and nutrition security were used. However, they were eventually divided into 3 groups of governing organizations, main responsible organizations and supporting organizations. The steering committee was mainly formed by the main responsible organizations and their decrees were issued by the Ministry of Health Deputy (Table 1). Simultaneously, for completing the strategies, the provincial nutrition officers presented their ideas through focus group discussion in a 1-day national meeting. After compiling the draft document, opinions of the steering committee members and the deputies of the Ministry of Health were collected. Following the classification of data into 3 separate areas of recognition, direction and implementation manner, data were prepared for formulation of policy documents and conveyed to the steering committee for revision and completion (Table 1).

The study protocol was approved by the Ethical Committee of the National Nutrition and Food Technology Research Institute (NNFTRI), Faculty of Nutrition Sciences and Food Technology, Shahid Beheshti University of Medical Sciences.

\section{Results}

\section{Recognition part}

\section{Reviewing all of the published secondary data, the current programmes}

Studies and reviews of current programmes revealed that the Islamic Republic of Iran is among the highrisk group of countries according to the international map of food security (13). Analysis of food security in the Iranian provinces (14) showed the following: very insecure: $\geq 83.3^{\text {th }}$ percentile of food security score $(n=$ 3: Hormozgan, Kohkilouieh and Boyerahmad, and Sistan and Baloochestan); insecure: 66.6-83.3th percentile ( $n=4$ : Khozestan, Kerman, Ilam, and Booshehr); relatively insecure: 50.0-66.6th percentile ( $n=7$ : Ardebil, Charmahal and Bakhtiari, Fars, Kermanshah, Kordestan, Lorestan, and South Khorasan); relatively secure: 33.3-50th percentile ( $n=8$ : Zanjan, West Azerbaijan, Razavi Khorasan, North Khorasan, Markazi, Hamedan, Golestan, and Gilan); secure: $16.7-33.3$ th percentile $(n=3$ : East Azerbaijan, Qazvin and Mazandaran); very secure: < 16.7th percentile ( $n=5$ : Qom, Isfahan, Semnan, Tehran, and Yazd).

The outcomes of the Iranian food and nutrition security system during the last 3 decades included the following.

- Development of managerial infrastructures. 


\begin{tabular}{|c|c|c|}
\hline \multicolumn{3}{|c|}{$\begin{array}{l}\text { Table } 2 \text { Designed conceptual framework of the national document on food and nutrition security bas } \\
\text { supply, food safety and nutrition } \\
\text { Fields } \\
\text { Focus points in } 3 \text { outcome areas of food and nutrition security }\end{array}$} \\
\hline Sustainable food supply & $\begin{array}{l}\text { 1. Conformity of producing main foods, with the desirable food basket designed to } \\
\text { provide all nutritional needs of the community. } \\
\text { 2. Producing raw agricultural products (plants, livestock and fisheries products) and } \\
\text { processed foods, with the highest safety and nutritional value } \\
\text { 3. Need to enhance nutritional knowledge of all activists in the food chain, including } \\
\text { farmers and livestock breeders, food processors, food distributors and suppliers, } \\
\text { food retailers and the media } \\
\text { 4. To promote production of healthy foods, related to the risk factors of prevalent } \\
\text { noncommunicable diseases } \\
\text { 5. Need to improve fair access to food (considering requirements of low-income } \\
\text { deciles and fair geographical distribution of foods) } \\
\text { 6. Need to prevent and manage effects of environmental factors on agriculture } \\
\text { 7. Need to ensure safe water for irrigation of farms that are at risk of human fecal } \\
\text { contamination }\end{array}$ & $\begin{array}{l}\text { Food availability and } \\
\text { accessibility }\end{array}$ \\
\hline Food safety & $\begin{array}{l}\text { 1. Compiling standards and supervising their application, by participation of all } \\
\text { stakeholders in the food chain } \\
\text { 1. Need for food labelling } \\
\text { 1. Need to educate and encourage all health activists in the food chain } \\
\text { 1. Need to improve healthy and safe food supply }\end{array}$ & Food utilization \\
\hline Nutrition & $\begin{array}{l}\text { 1. System of assuring sustainable supply of healthy foods for all age groups, and } \\
\text { food safety in production and supply processes } \\
\text { 2. System of intrasectorial cooperation in reducing nutrition- related diseases, and } \\
\text { providing nutritional health at the beginning of life, with cooperation of other } \\
\text { related organizations } \\
\text { 3. System of developing and revising policies and food and nutrition guidelines for } \\
\text { different groups } \\
\text { 4. Enhancing nutritional literacy of food producers and suppliers } \\
\text { 5. Improving nutritional services at hospitals } \\
\text { 6. Managing nutrition in crises } \\
\text { 7. Improving quality of current programmes for enhancing nutritional culture and } \\
\text { literacy } \\
\text { 8. Improving micronutrient status } \\
\text { 9. Need to develop food and nutrition surveillance system, and assuring nutrient } \\
\text { satiety and nutritional health of community }\end{array}$ & \\
\hline
\end{tabular}

- Elimination of iodine deficiency disorders and decreasing the prevalence of goitre from $69 \%$ in 1990 to $4.8 \%$ in 2007 , through a salt iodizing programme (15-17).

- Improvement of food production index (increasing from 108.2 in 2007 to 109.3 in 2010) (18) and its geographical distribution (20). Food distribution index based on food cost showed that the difference between the 1st and 10th deciles of income of urban households was $8.8 \%$. Also, mean food cost/year of urban and rural households was 26157000 and 26137 ooo Rials, respectively. In 2012, the mean proportion of the food cost in urban and rural areas was $23 \%$ and $37 \%$, respectively (unpublished data).

- Improvement in access (96.8\% of households) to safe drinking water.

- Improvement in care of pregnant women and breastfeeding ( $56 \%$ of infants aged 0-6 months). Reduction in low birth weight $(7.7 \%)$ and childhood mortality (20.1\% in infants aged $<1$ year) (21-24). In this regard, we should not ignore the effect of closing the gap in literacy among men and women (literacy rate: $99 \%$ in both genders) in improving family health in the last 3 decades $(25,26)$.
- Underweight, wasting and stunting have had an improving trend among children aged $<5$ years in the past 3 decades. Nationwide surveys in 1995, 1997 and $2009(16,21,27,28)$ showed that prevalence of malnutrition had substantially reduced over these years. In children aged $<5$ years, prevalence of underweight was reduced from $13.8 \%$ in 1995 to $9.5 \%$ in 1998 and $4.6 \%$ in 2004 . Also, prevalence of wasting and stunting was reduced from $4 \%$ to $3.7 \%$ and $6.83 \%$ to $4.7 \%$, respectively, in 2004 in comparison with 1995.

- Despite this improvement, prevalence of child malnutrition is still 3 times more than the national average in deprived areas. Also, micronutrient deficiency is high among vulnerable groups: $39,21.4,16$ and 56\% of pregnant women suffer from zinc deficiency, anaemia, vitamin A deficiency and moderate-to-severe vitamin D deficiency, respectively; 2 and $4 \%$ of children aged 15-23 months suffer from severe vitamin A and $\mathrm{D}$ deficiencies, respectively, based on the results of the last National Integrated Micronutrients Survey (NIMS) (21,29).

- Increases in average food expenses during the last decade have resulted in decreased calorie intake in rural areas, especially among lower-income deciles; 
increased calorie intake among high-income deciles in urban areas; and an imbalance in calorie intake among rural households, which have all caused side effects of both under- and overnutrition in the community (30).

- High consumption of carbonated drinks and salt in all provinces, high consumption of low nutritional value foods like canned foods and fast foods, especially in large cities, and decreased consumption of fish and fresh fruit and vegetables, have all resulted in an increasing trend in overweight and obesity, and noncommunicable diseases (14,26): 43.95, 2.7, and 3.6\% of Iranians are overweight and obese, diabetic, and taking antihypertensive medication, respectively $(31,32)$.

- In the study of determining Iranians' food basket (shopping pattern) in 2012, it was shown that consumption of milk and dairy products, fruit and vegetables was lower, and sugar, fat and oil consumption was higher than the recommended amounts (30).

- Review of the governmental and ministerial rules and regulations revealed that there are adequate legislation and national programmes for making operational an integrated food and nutrition security improvement programme in the Islamic Republic of Iran. However, for operationalization of the rules and regulations, establishing an intersectorial headquarters for programming and monitoring seems necessary.

\section{Stakeholder situation analysis}

According to the data obtained from interviews, governmental and ministerial documents and opinions of steering committee members in focus group discussions indicated that there are 6 focus points to be considered in improving the indicators of nutrition and food security: (1) need to improve indicators for undernutrition (underweight, wasting and stunting) and overnutrition (overweight and obesity) among children aged < 5 years; (2) need to improve micronutrient status among vulnerable groups including women of gestational age, especially those who are pregnant, children aged $<5$ years, adolescents during puberty and elderly people; (3) need to improve indicators of nutritionrelated noncommunicable diseases (heart attack, stroke, hypertension and diabetes); (4) need to improve fair access to major food groups (improving access of low-income deciles and those who live in certain geographical areas); (5) urgent action for the provinces that are relatively to highly insecure; and (6) need to improve access to healthy and nutritious foods.

Analysis of the current programmes of the Nutrition Department of the Iranian Ministry of Health and Medical Education revealed an absence of the following programmes and systems: (1) system of securing and assuring sustainable safe food supply for different age groups and establishing food safety in production and distribution processes; (2) system of intrasectorial cooperation for reducing nutrition-related diseases and providing a healthy diet at the beginning of life; (3) system of developing and revising the policies and guidelines for food and nutrition for different groups; (4) enhancing nutritional knowledge and literacy of food producers and suppliers; and (5) supervising nutritional services at hospitals and managing nutrition during crises.

Analysis of the current programmes of the Iranian Food and Drug Organization, National Standard Organization, Ministry of Health Centre For Environmental and Professional Health, and Undersecretary of State for Public Health showed that there is some overlap in the supervisory and integrated control roles and responsibilities for food safety, from production to supply, which causes wasting of resources, reduced quality control, and less monitoring of food producers and suppliers in meeting the regulations.

\section{Orientation part}

According to the evidence and the designed conceptual model, the landscape approved by the stakeholders and health experts for 2021 is as follows:

The main responsible organizations for the country's food and nutrition security system must improve the fair physical and economic access to food, and also the indicators of undernutrition, overnutrition and their outcomes (to the predicted level of this programme) by year 2021, through establishing: (1) intersectorial cooperation; (2) achieving people's participation: and (3) placing all of the provinces in desirable food and nutrition security status, so that the Islamic Republic of Iran's ranking can be enhanced in the region.

Table 3 shows those objectives for 2016 and 2021.

\section{Establishment part}

To achieve the strategic objectives of 2016 and 2021, 20 interventions have been defined, approved and issued based on the budgets and legal responsibilities of the national organizations (Table 4). This document was approved by the High Council of Health and Nutrition Security, and notified to all ministers and provincial governor-generals.

Although progress is mostly the resultof organizational learning and development and establishment of the policy documents (32), there remains the issue of high manager turnover. Therefore, it was imperative that the programme was implemented in 4 phases as follows: (1) preparing for establishment (1st half of 2013); (2) laying the ground for interventions (2nd half of 2013); (3) interventions related to outcome level indicators (20142015); and (4) evaluation and decision making for the next programme (end of 2015).

This national document was approved and communicated by the Minister of Health to the Ministers of Agriculture, Industry \& Commerce, Cooperatives, Labor \& Social Welfare and National Standard Organization, as well as Chairpersons of the Supreme Council of the Provinces, Media, and Chamber of Commerce, Industries 


\section{Table 3 Strategic objectives of the national document on food and nutrition security}

Outcome targets for 2016

1. Increasing nutritional literacy of target groups, by $\geq 50 \%$ compared with base year

2. Increasing average amounts of fruit, vegetables, milk and dairy produce, and pulses by $15 \%$ compared with base year

3. Increasing access to whole grains and their consumption by $20 \%$ compared with base year

4. Decreasing the amounts of salt, sugar and fats in foods and beverages by $\geq 30 \%$ compared with base year

5. Decreasing at least $30 \%$ of the main risk factors of agriculture products, by approval of the High Council of Health and Nutrition Security

6. Notifying prioritized standards of the food chain to all responsible for its control, based on risk assessment, in at least $50 \%$ of implementing centres, with determination of the priorities by the High Council of Health and Nutrition Security

7. Public announcement of the rank of major food producers, according to the policies of safety and nutritional value

8. Establishing at least 1 nutrition consultation visit for obese children, adolescents, adults, pregnant women and elderly people, in family physician programmes, and follow up visits for $50 \%$ of them

9. Maintaining and improving the coverage of iodized and refined salt consumption in $\geq 99 \%$ of households

10. Establishing a system of food and nutrition management in the provincial crisis management systems (designing, justifying, educating and implementing manoeuvres)

11. Full establishment of nutritional labelling for all processed food products, proportionate to the level of people's nutritional knowledge

12. Controlling the required hospital food solutions and supplements, based on current standards

13. Implementing $\geq 30 \%$ of the approved standards of the Ministry of Health and Medical Education on nutrition consultation services at hospitals

14. Standardizing food units of hospitals by end of 2014

15. Notifying and promoting regulation and policies for improving nutrition in public places, with priority for restaurants, kindergartens and schools, and at least 1 monitoring session and presenting feedback

16. Establishing food and nutrition security surveillance system, and publishing annual reports on it (for some indicators, bi- or triannual reports should be published)

17. Establishing of programmes for food fortification and supplementation of iron, zinc and vitamins A and D; both in the food industry and for primary prevention

18. Publishing the desirable food basket (collecting data on food per capita and food consumption patterns for different age and sex groups) in the 4 th year of the 5-year development programmes

\section{Outcome targets for 2021}

1. Decreasing the prevalence of protein-energy malnutrition among children aged < 5 years, pregnant mothers and elderly people, by $30 \%$ compared with base year

2. Decreasing the prevalence of food-borne diseases by $20 \%$ compared with base year

3. Increasing the chance of people to make informed choices using food labelling, by $50 \%$ compared with base year

4. Decreasing the prevalence of overweight and obesity among children, adolescents, adults and elderly people by $30 \%$ compared with base year

5. Decreasing the prevalence of common micronutrient deficiencies (iodine, iron, zinc, vitamins A and D) among children aged $<6$ years, adolescents, and pregnant and lactating women, by $20 \%$ compared with base year

6. Decreasing the prevalence of goitre among children aged 8-10 years, by $10 \%$ compared with current situation

7. Improving quality of foods by $50 \%$ in restaurants of universities, factories, offices and prisons, etc.

8. Improving the indicators of hospital nutrition by $\geq 30 \%$

and Mines in 2012 (33). This programme has been running for 2 years. For effective implementation, the High Council of Health and Nutrition Security formed an intersectorial nutrition and food security working group (for seasonal monitoring of operations of the document) to develop a general memorandum of understanding with the main organizations, universities, media and representatives of the people and private sector; encourage successful organizations; and rank the provinces based on their practices.

The final product of this project is the road map to Iranian food and nutrition security until 2021. To the best of our knowledge, no organized national document for food and nutrition security has been established in countries of WHO Eastern Mediterranean Region. Alwan states that "lack of comprehensive food safety laws, regulations and standards are considered the major challenges for food safety systems in the region" (34). So, the present document in believed to be the first national document of its kind in the Region.

During the past decade, some national programmes on food and nutrition security were designed and implemented, including the national document for intersectorial food and nutrition security development (2005; under an Act of the 4th Development Programme), and the executive package of food and nutrition security (2010; under an Act of the 5th Development Programme). However, none of them gained sufficient legitimacy, mostly due to the fact that they did not have ownership in any sector and/or their operationalization and monitoring systems were not clear $(18,25,34)$. The World Bank is the largest international provider of financial resources for nutrition programmes. From the Bank's point of view, the most important obstacle for effective use of resources for nutrition programmes is the lack of a responsible authority for implementing the programmes and interventions. According to a study by the Bank in 2000, most nutrition programmes fail at the implementation phase (35). To develop the current national document, a lot of effort has been made to overcome those weaknesses. Comparison of the current national document with previous ones shows the added value of the former (Table 5). Progress has mostly resulted from organizational learning of the methods for developing and establishing 


\begin{tabular}{|c|c|c|}
\hline Areas & Programmes & Responsible organizations \\
\hline Sustainable food supply & $\begin{array}{l}\text { 1. Producing safe agricultural products } \\
\text { 2. Availability of main foods and assuring the appropriate market } \\
\text { 3. Healthy formulation of produced foods } \\
\text { 4. Obligatory and optional nutrient fortification of the main and } \\
\text { complementary foods } \\
\text { 5. Effective economic tools on appropriate and healthy nutrition } \\
\text { (taxes, subsidies, loans) } \\
\text { 6. Managing the effects of climate change on food and nutrition } \\
\text { security }\end{array}$ & $\begin{array}{l}\text { Ministry of Agriculture and Veterinary } \\
\text { Organization } \\
\text { Ministry of Industry, Mining and } \\
\text { Commerce } \\
\text { Ministry of Economy and Environment } \\
\text { Organization }\end{array}$ \\
\hline Food safety & $\begin{array}{l}\text { 7. National network of food monitoring } \\
\text { 8. Labelling of food products } \\
\text { 9. Improving safety level and decreasing main risk factors of } \\
\text { prioritized food and agricultural products } \\
\text { 10. Cyclical ranking of food and beverage production and supply } \\
\text { centres } \\
\text { 11. Supplying safe and healthy foods } \\
\text { 12. Integrated supervision and updating of the food chain, based } \\
\text { on risk assessment }\end{array}$ & $\begin{array}{l}\text { Food and Drug Organization } \\
\checkmark \text { National Standard Organization } \\
\checkmark \text { Centre of Environmental and } \\
\text { Professional Health of MOHME }\end{array}$ \\
\hline Nutrition & $\begin{array}{l}\text { Program 13: Nutritional health at the beginning of life } \\
\text { Program 14: Policies and guidelines of food and nutrition } \\
\text { Program 15: Improving nutritional literacy and encouraging food } \\
\text { producers and consumers to producing and consuming high } \\
\text { nutritional value foods } \\
\text { 16. Assuring the synergy of intra- and intersectorial organizations' } \\
\text { programmes for providing appropriate and healthy nutrition } \\
\text { 17. Establishing supportive programmes for vulnerable groups } \\
\text { 18. Nutritional care of different age groups in family physician } \\
\text { programmes and the referral system } \\
\text { 19. System of nutritional care and food safety in hospitals } \\
\text { 20. Managing nutrition in crises }\end{array}$ & $\begin{array}{l}\checkmark \text { Nutrition Department of Iran's } \\
\text { MOHME }\end{array}$ \\
\hline
\end{tabular}

MoHME = Ministry of Health and Medical Education.

the policy documents (33).

Establishment of a food and nutrition security expert panel by the Ministry of Health and Medical Education, and inviting representatives of other organizations as members, as well as motivating them, will strengthen intersectorial cooperation, and the exhausting process of traditional follow-up will be replaced by enhancement of responsibility and accountability of the stakeholders. Establishment of a system of project management and using the results at headquarter level, organization of a method of monitoring universities, and using the experiences of expert communities will improve establishment of the document.

The inclusion of 3 committee members for intrasectorial coordination will mean a lot of discord should be omitted inside the Ministry of Health and Medical Education. There are 3 complementary functions that will require integrated team work: (1) supervision of food safety at the pre-supply level by the Food and Drug Organization; (2) supervision of food safety at the supply level by the Environmental and Occupational Health Centre; and (3) enhancement of nutritional literacy of the community, determining the standards of healthy nutrition and developing nutritional interventions for improving people's life style by the Department of Nutrition. In this regard, however, it is necessary to try to remove the overlapping responsibilities of the Food and Drug Organization and National Standard Organization.
The present study had some limitations. One of the main limitations was access to intersectorial data. Also, there were no available data in the food safety area. The main strength of this work was the ability to design and develop the document based on a national policy format that made it assessable. Also, it was developed by intersectorial collaboration with the 4 main stakeholders. Another significant strength of the work was the fact that the developed document for food and nutrition security was announced bythe Ministry of Health and Medical Education. The food and nutrition security model (4) was considered while developing the document.

\section{Conclusion and recommendations}

The main outcomes of this study can be summarized as follows: (1) a national document of food and nutrition security was developed and approved; (2) responsibilities of the related organizations were agreed through signing a memorandum of understanding by the 8 involved organizations; and (3) requirements for establishing the document including human resources, an appropriate structure and financial resources, have been considered, and executive operation of the document was monitored by supervising committees.

It is hoped that the assistance of all managers and experts in the Iranian health network and cooperation of all medical universities will enable the developers of this document to reach its strategic objectives. In this regard, 


\begin{tabular}{|c|c|c|}
\hline Criteria of comparison & Previous programmes & Current programme \\
\hline Situation analysis & $\begin{array}{l}\text { Mostly on the basis of nutritional } \\
\text { indicators }\end{array}$ & $\begin{array}{l}\text { Situation analysis of food and nutrition security system } \\
\text { Considering indicators of output and outcome levels ( } 2016 \text { and 2021) } \\
\text { Situation analysis of current programmes or mental health } \\
\text { interventions } \\
\text { Using latest national evidence }\end{array}$ \\
\hline $\begin{array}{l}\text { Participation of } \\
\text { stakeholders }\end{array}$ & $\begin{array}{l}\text { Duties were not clear in the programmes, } \\
\text { except in the national document of } \\
\text { intersectorial development }\end{array}$ & $\begin{array}{l}\text { Participation of headquarter (Ministry of Health and Medical } \\
\text { Education) units and determining expectations from them } \\
\text { Determining duties of governmental, ministerial and intersectorial } \\
\text { organizations } \\
\text { Participation of nutrition experts, both at headquarter and in the } \\
\text { provinces } \\
\text { Collective participation and consensus of the country's nutrition } \\
\text { experts }\end{array}$ \\
\hline $\begin{array}{l}\text { Using different } \\
\text { interventions }\end{array}$ & $\begin{array}{l}\text { Inadequate notice to the comprehensive } \\
\text { conceptual model }\end{array}$ & $\begin{array}{l}\text { Using the conceptual model and interventions of each of them, and } \\
\text { considering the definition of nutrition security instead of food security, } \\
\text { for sustainable food supply, food safety and nutrition }\end{array}$ \\
\hline International experiences & Inadequate use of international reports & $\begin{array}{l}\text { Most of the published reports on food and nutrition (after 2000) have } \\
\text { been used }\end{array}$ \\
\hline $\begin{array}{l}\text { Considering the } \\
\text { governmental and } \\
\text { ministerial rules } \\
\text { and regulations and } \\
\text { development programmes }\end{array}$ & Limited reliance & $\begin{array}{l}\text { A wide spectrum of superior and intersectorial documents } \\
\text { Concomitance with the } 5 \text { th and 6th development programmes }\end{array}$ \\
\hline $\begin{array}{l}\text { Legitimacy of the } \\
\text { programme }\end{array}$ & $\begin{array}{l}\text { Approved (by Parliament) } 5 \text { th } \\
\text { development programme, and approved } \\
\text { (by cabinet) A comprehensive map of } \\
\text { health system reform }\end{array}$ & $\begin{array}{l}\text { Approval of policy making council } \\
\text { Approval of High Council of Health and Nutrition Security } \\
\text { Notification of the Deputy for Public Health Affairs } \\
\text { Notification of Food and Drug Organization }\end{array}$ \\
\hline $\begin{array}{l}\text { System of establishment } \\
\text { and its operationalization }\end{array}$ & There is no evidence in most cases & $\begin{array}{l}\text { Requirements of establishing the programme, as the division of } \\
\text { tasks, preparing a headquarters and experts, the operational structure, } \\
\text { method of establishing the document at provincial level, and inter- and } \\
\text { intrasectorial memoranda of understanding }\end{array}$ \\
\hline
\end{tabular}

the supportive and supervising role of the Ministry of Health and Medical Education, specifically the Nutrition Department, should not be neglected. In other words, monitoring the practice of medical universities requires some practical changes in the Ministry. For this purpose, the organizational structure of the Nutrition Department must be revised and developed based on its main functions. At primary revision, the main functions of Department have been determined as the following 5 programmes: (1) enhancing nutritional culture and literacy; (2) revising and compiling nutritional protocols and standards; (3) intra- and intersectorial synergy; (4) studies, evaluations and surveillance; and (5) nutrition in crisis conditions.

Experts in the Department of Nutrition must consider new ways of working. In accordance with the skills of most universities of medical sciences in education, research and service provision, the protocol for establishing this document should be notified to them as a guideline. This could also be an appropriate tool for evaluating and ranking universities.

Furthermore, there are some international recommendations proposed regarding the development of the national document for food and nutrition security: (1) use of this template to assess the situation and develop national programmes of food and nutrition security in the Eastern Mediterranean Region and improve the model proposed in this paper; and (2) communication of a protocol for storage and collection of data for food and nutrition security by the WHO and monitoring and comparing data periodically.

\section{Acknowledgements}

We would like to thank the Parliamentary Research Centre for helping us to obtain the documents and evaluate the reports of other organizations. We would also like to thank the Ministries of Health, Agriculture, Industry \& Commerce and National Standard Organization, The Presidential Deputy of Planning and Supervising, Food and Drug Department of the Ministry of Health and Medical Education, Centre of Environment and Occupational Health of Ministry of Health and Medical Education, Hospital and Health Services Management Office of Ministry of Health and Medical Education, other 
ministries and collaborative organizations in the field of nutrition and food security for their intersectorial collaboration. We specially appreciate Dr. Forouzan Salehi, Ms. Farzaneh Sadeghi (Nutrition Department experts at Ministry of Health and Medical Education) and Dr. Ali Keshavarz (Superior Coordinator of the Project) for their effective collaboration in this project.

Funding: This work was supported by the Iranian Ministry of Health Department for Improving Nutrition, and National Nutrition \& Food Technology Research Institute (grant numbers 1656 and 3844).

Competing interests: None declared.

\section{Politiques en matière de sécurité alimentaire et nutritionnelle en République islamique d'Iran : analyse de situation et feuille de route à l'horizon 2021}

\section{Résumé}

Contexte : Les politiques et lesprogrammes menés par le gouvernement en matière de sécurité alimentaire et nutritionnelle devraient tous permettre la fourniture d'aliments sains, et garantir que ces aliments soient économiquement abordables et socialement accessibles.

Objectif : La présente étude avait pour objectif d'analyser la situation actuelle de la sécurité alimentaire et nutritionnelle en République islamique d'Iran, ainsi que d'établir une feuille de route à l'horizon 2021.

Méthodes: Les méthodes utilisées pour cette étude étaient l'analyse de situation et une méthode regroupant les approches qualitative et quantitative. La méthode conceptuelle utilisée pour l'élaboration de ce document national englobait trois domaines : l'approvisionnement alimentaire durable, la sécurité sanitaire des aliments et la nutrition.

Résultats : Les réalisations du système de sécurité alimentaire et nutritionnelle iranien au cours des 30 dernières années incluent la mise en place de structures de prise en charge et l'amélioration de la situation de la sécurité alimentaire et nutritionnelle. Néanmoins, une analyse des programmes actuels a montré que les rôles de certaines organisations œuvrant dans le domaine se chevauchaient et s'entrecoupaient en matière de supervision de la sécurité sanitaire des aliments (de la production à l'approvisionnement), et que des travaux similaires avaient été menés en parallèle. Le document national produit à l'issue de cette étude a été communiqué par le ministère iranien de la Santé en 2012, et a été appliqué pendant deux ans. Les ministères sélectionnés sont responsables de la mise en œuvre de 20 programmes nationaux d'ici la fin du Cinquième Programme de développement économique, social et culturel (2011-2016). Les parties prenantes ont convenu que d'ici la fin du Sixième Programme de développement (2021), l'ensemble des provinces jouiront d'une sécurité alimentaire et nutritionnelle solide voire renforcée.

Conclusion : Le défi le plus important dans l'établissement de documents nationaux consiste à les rendre opérationnels. Cet objectif a été atteint par un groupe de travail intersectoriel sur la sécurité nutritionnelle et alimentaire, qui a produit un mémorandum d'accord avec les principales organisations, les médias, les universités et le secteur privé.

$$
\begin{aligned}
& \text { سياسة التغذية والأمن الغذائي في جمهورية إيران الإسالامية: تحليل حالة وخارطة طريث نحو عام ا ب ب r } \\
& \text { بهز اددماري، زهر اعبد اللهي، مجيد حاجي فرجي، آرزو رضاز اده } \\
& \text { الخالاصة } \\
& \text { الهدف: تمثل الهدف من هذه الدر اسة في تحليل الحالة الر اهنة للأمن الغذائي والتغذوي في إيران ووضع خارطة طريق حتى عام اب ·. . . } \\
& \text { طرق البحث: استخدم تحليل الحالة وطريقة كيفية - كمية تختلطة للبحث في هذه الدراسة. وتضمن الإطار المفاهيمي المستخدم لوضع هذه هذه الوثيقة }
\end{aligned}
$$

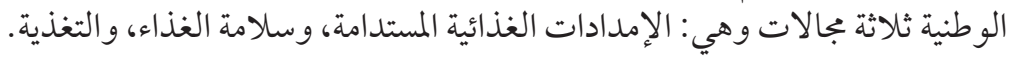

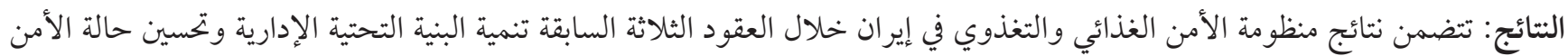

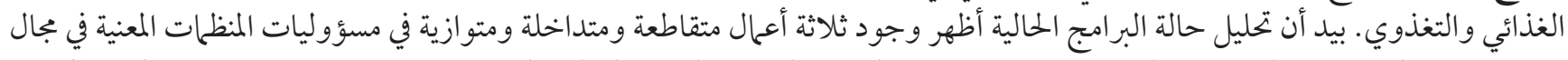

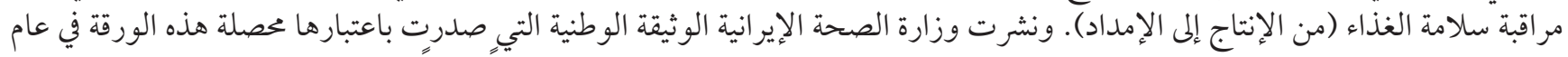

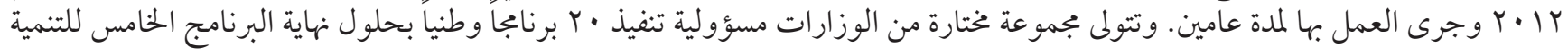

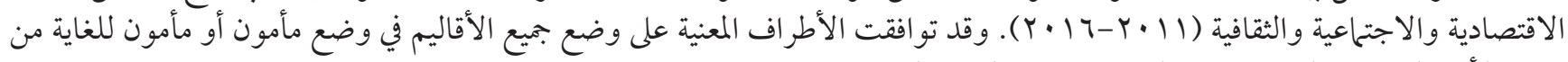

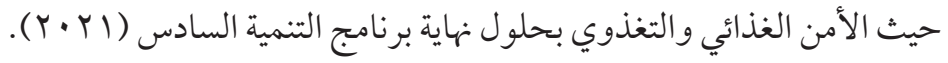

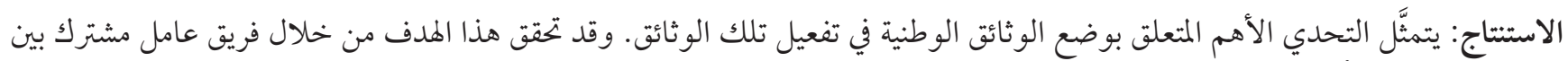

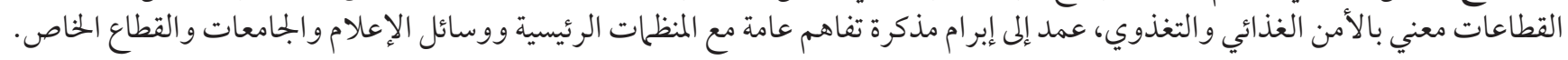




\section{References}

1. Venugopal KR. Food security vs. nutrition security. Health Millions. 1999 Mar-Apr;25(2):18-9. PMID:12295422

2. Ismail SJ, Immink MDC, Mazar I, Nantel G. Community-based food and nutrition programmes: what makes them successful: a review and analysis of experience. Rome: Food and Agriculture Organization; 2003.

3. Alwan A, Elmi M. Food safety in the Eastern Mediterranean Region: time to act. East Mediterr Health J. 2015;21(3):153-4. http:// apps.who.int/iris/bitstream/10665/255049/1/EMHJ_2015_21_3_153_154.pdf

4. Gross R, Schoeneberger H, Pfeifer H, Preuss $H$. The four dimensions of food and nutrition security: definitions and concepts. Bonn: nWEnt - Capacity Building International; 2000 (http://fpmu.gov.bd/agridrupal/sites/default/files/Four_Dimension_of_ FS.pdf, accessed 4 December 2017).

5. Evans A. The feeding of the nine billion: global food security for the 21st century. A Chatham House Report. London: Chatham House; 2009 (http://citeseerx.ist.psu.edu/viewdoc/download?doi=10.1.1.170.1355\&rep=rep1\&type=pdf, accessed 4 December 2017).

6. Alwan A, editor. Global status report on noncommunicable diseases 2010. Geneva: World Health Organization; 2011 (http://apps. who.int/iris/bitstream/10665/44579/1/9789240686458_eng.pdf, accessed 4 December 2017).

7. Ghassemi H, Harrison G, Mohammad K. An accelerated nutrition transition in Iran. Public Health Nutr. 2002 Feb;5(1a):149-55. http://dx.doi.org/10.1079/PHN2001287 PMID:12027278

8. Rezazadeh A, Rashidkhani B, Omidvar N. Association of major dietary patterns with socioeconomic and lifestyle factors of adult women living in Tehran, Iran. Nutrition. 2010 Mar;26(3):337-41. http://dx.doi.org/10.1016/j.nut.2009.06.019 PMID:19819112

9. Asghari G, Rezazadeh A, Hosseini-Esfahani F, Mehrabi Y, Mirmiran P, Azizi F. Reliability, comparative validity and stability of dietary patterns derived from an FFQ in the Tehran Lipid and Glucose Study. Br J Nutr. 2012 Sep 28;108(6):1109-17. http://dx.doi. org/10.1017/Sooo7114511006313 PMID:22251608

10. Esmaillzadeh A, Azadbakht L. Major dietary patterns in relation to general obesity and central adiposity among Iranian women. J Nutr. 2008 Feb;138(2):358-63. PMID:18203904

11. Vosoogh Moghaddam A, Damari B, Alikhani S, Salarianzedeh M, Rostamigooran N, Delavari A, et al. Health in the 5th 5-years Development Plan of Iran: main challenges, general policies and strategies. Iran J Public Health. 2013 01 1;42 Supple1:42-9. PMID:23865015

12. Mohammadi-Nasrabadi F, Omidvar N, Khoshfetrat MR, Kolahdooz F. Household food insecurity in the Islamic Republic of Iran: a systematic review and meta-analysis. East Mediterr Health J. 201412 17;20(11):698-706. PMID:25601808

13. The state of food insecurity in the world 2015. Rome: Food and Agriculture Organization of the United Nations; 2015 (http://www. fao.org/3/a-i4646e.pdf, accessed 4 December 2017).

14. Kolahdouz FNF, Sadeghi F, editors. National System for monitoring food security and nutrition situation in Iran and development of the first map of food security in the country. Tehran: Department of Community Nutrition, Ministry of Health and Medical Education; 2012

15. National guide of nutrition during pregnancy and lactation, a collection of books on nutrition for the family doctor, community health offices, families and schools. Tehran: Department of Community Nutrition, Ministry of Health and Medical Education; 2007.

16. Report of the results of determine the appropriate interventional pattern to reduce malnutrition in children under five years and its evaluation in rural areas of Ilam, Borazjan Bardsir city. Tehran: Department of Community Nutrition, Ministry of Health and Medical Education; Department of Epidemiology and Biostatistics, Tehran University of Medical Sciences; 2001.

17. Azizi F, editor. Report of fourth national monitoring program for prevention and control of iodine deficiency disorders in the Islamic Republic of Iran in 2007. Tehran: Department of Community Nutrition, Ministry of Health and Medical Education; Research Institute for Endocrine Sciences, Shahid Beheshti University of Medical Sciences; 2011.

18. Sadeghiyan Sharif, Sadeghi ghotb Abadi F. Ahmadi, Sh. Habibi, d. Roozbahani, M. Food baskets and nutritional needs in the crisis and the role of agricultural production. Tehran: Department of Community Health, Ministry of Health and Medical Education \& Ministry of Agriculture Engineering Research; 2010.

19. Analytical report of the situation of wheat, flour and bread in Iran and approvals of the National council of food and nutrition. Tehran: Department of Community Nutrition, Ministry of Health and Medical Education; 2004.

20. Minaei M. Sadeghi ghotb Abadi F, Kamali B, Janjany H. Executive instructions of nutritional support for pregnant and lactating women. Tehran: Ministry of Health and Medical Education, Deputy of the Imam Khomeini Relief Committee, family support, social studies and Poverty Alleviation Office of the Ministry of Welfare and Social Security; 2007.

21. Sadeghi SHTP, Minaei M, Sadeghi Ghotb Abadi F, Sadeghiyan Sharif S. Guidelines for nutrition education in different periods of life (particularly staff development and social welfare). Tehran: Department of Community Nutrition, Ministry of Health and Medical Education; 2010.

22. Features of child nutrition. Tehran: Community Nutrition Office, Ministry of Health and Medical Education; 2001.

23. Features of child nutrition in the provinces of Iran. Tehran: Ministry of Health and Medical Education; New York: The United Nations Children's Fund (UNICEF).

24. Sadrzadh YHM, Abdollahi Z, Fallah H. Report of assessing the effectiveness of programs through food baskets to support the nutritional needs of pregnant and lactating women suffering from malnutrition in Chaharmahal and Bakhtiari province. Tehran: 
Faculty of Nutrition and Diet, Tehran University of Medical Sciences; Department of Community Nutrition, Ministry of Health and Medical Education; 2012.

25. Deputy of Targeted Subsidies and Social Welfare. Project of providing food basket to needy families with children under 6 years. Tehran: Ministry of Welfare and Social Security; 2008.

26. Aminpour A. Guidelines for identifying and management of overweight/obesity among children and adolescents. Tehran: Department of Nutrition, Department of Family Health, Ministry of Health and Medical Education; Shahid Beheshti University of Medical Science; 2011.

27. The rate of preterm delivery, low birth weight and its influencing factors in different climates of Iran. Tehran: Department of Community Nutrition, Ministry of Health and Medical Education; New York: United Nations Children's Fund; 2007.

28. Growth and nutrition improvement of children. Tehran: Department of nutrition improvement, Ministry of Health and Education; 2005.

29. National micronutrients survey of Iranians. Tehran: Nutrition improvement office,: Ministry of Health and Medical Education; 2011.

30. Map of the health system transformation. Tehran: Department of Community Nutrition, Ministry of Health and Medical Education; 2012.

31. National document of nutrition and food security (2013-2022). Tehran: Ministry of Health and Medical Education; 2013.

32. Hajebi A, Damari B, Vosoogh Moghaddam A, Nasehi A, Nikfarjam A, Bolhari J. What to do to promote mental health of the society. Iran J Public Health. 2013 Jan 1;42(Suppl 1):105-12. PMID:23865026

33. Damari B. The final report of the project of assessment, analysis and development of national nutrition and food security document (2012-2015). Tehran: National Institute of Health Research; 2013.

34. Alwan A. WHO events addressing public health priorities. East Mediterr Health J. 2015;20(8):521-3.

35. Rokx C. Who should implement nutrition interventions? The application of institutional economics to nutrition and the significance of various constraints to the implementation of nutrition interventions. Washington: World Bank; 2000. 